\title{
Temporal order and processing acuity of visual, auditory, and tactile perception in developmentally dyslexic young adults
}

\author{
MARJA LAASONEN, ELISABET SERVICE, and VEIJO VIRSU \\ University of Helsinki, Helsinki, Finland
}

\begin{abstract}
We studied the temporal acuity of 16 developmentally dyslexic young adults in three perceptual modalities. The control group consisted of 16 age-and IQ-matched normal readers. Two methods were used. In the temporal order judgment (TOJ) method, the stimuli were spatially separate fingertip indentations in the tactile system, tone bursts of different pitches in audition, and light flashes in vision. Participants indicated which one of two stimuli appeared first. To test temporal processing acuity (TPA), the same 8-msec nonspeech stimuli were presented as two parallel sequences of three stimulus pulses. Participants indicated, without order judgments, whether the pulses of the two sequences were simultaneous or nonsimultaneous. The dyslexic readers were somewhat inferior to the normal readers in all six temporal acuity tasks on average. Thus, our results agreed with the existence of a pansensory temporal processing deficit associated with dyslexia in a language with shallow orthography (Finnish) and in well-educated adults. The dyslexic and normal readers' temporal acuities overlapped so much, however, that acuity deficits alone would not allow dyslexia diagnoses. It was irrelevant whether or not the acuity task required order judgments. The groups did not differ in the nontemporal aspects of our experiments. Correlations between temporal acuity and reading-related tasks suggested that temporal acuity is associated with phonological awareness.
\end{abstract}

Developmental dyslexia is a specific problem in reading, often accompanied by difficulties of acquiring proficiency in writing and spelling (Orton Dyslexia Society, 1994). The primary causes of dyslexic difficulties are still unclear. The prevailing opinions of possible causal factors can be divided into three broad classes: centralist, perceptual, and multifactor hypotheses.

Centralist hypotheses assume that developmental dyslexia results directly from difficulties in language (Vellutino, 1978), especially in phonological processing (Bradley \& Bryant, 1978, 1983; Vellutino, 1978; see Snowling, 2000 , for a review). Other possible impairments (e.g., perceptual and motor) are assumed to be independent of these true verbal dyslexic difficulties (Mody, Studdert-Kennedy, \& Brady, 1997; Shaywitz et al., 1998).

Perceptual hypotheses assume that perceptual problems are sufficient to deteriorate orthographic (e.g., Lovegrove, 1993) and phonological (e.g., Tallal, 1980) processing. Currently, the most investigated hypotheses assume that processing of rapidly changing temporal sequences is impaired in developmental dyslexia and that the impairment itself is a sufficient cause of phonological or other reading problems (Farmer \& Klein, 1995; Galaburda \&

This study was financially supported by the Ministry of Education, Finland, and the Academy of Finland (Project Nos. 157426,39253, and 174080). The authors thank S. Salminen for building and programming the apparatus. Correspondence should be addressed to M. Laasonen, Department of Psychology, P. O. Box 13 (Meritullinkatu 1), 00014 University of Helsinki, Finland (e-mail: marja.laasonen@ helsinki.fi).
Livingstone, 1993; Galaburda, Menard, \& Rosen, 1994; Livingstone, Rosen, Drislane, \& Galaburda, 1991; Lovegrove, 1993; Stein \& Walsh, 1997; Tallal, 1980; Tallal, Merzenich, Miller, \& Jenkins, 1998).

Multifactorhypotheses assume that perceptual deficits exist in dyslexia and are markers of dysfunctional neural systems. These systems trigger or relate to other mechanisms (e.g., attention) that affect orthographic or phonological processing in a more direct way. How independent the intermediate system is thought to be of the perceptual processing deficit varies. For example, the first versions of the "magnocellular-deficit" theory assumed that the transient (magnocellular, or $\mathrm{M}$ ) and sustained (parvocellular, or P) systems in vision interact so that, because of an M-deficit, the transient system does not erase the trace of a previous fixation, and, thus, the preceding stimulation can partially fuse with the next (Breitmeyer, 1980; Lovegrove, Martin, \& Slaghuis, 1986; Lovegrove, Garzia, \& Nicholson, 1990; ). An M-deficit could also give rise to a right parietal lobe dysfunction. This would result in impaired attentional functions' affecting both orthographical and phonological processes required in reading (Hari, Renvall, \& Tanskanen, 2001; Vidyasagar, 1999). There is direct anatomical and psychophysiological evidence for an M-deficit in at least some forms of dyslexia (Demb, Boynton, \& Heeger, 1998; Galaburda et al., 1994; Livingstone et al., 1991). This, together with a wealth of indirect evidence, has been taken as justification to extend the M-deficit explanation to reading difficulties generally, either directly 
or via an intermediate mechanism (for a review, see Stein \& Walsh, 1997).

The second and third types of explanation often take for granted that developmentaldyslexia is linked to, or caused by, impaired processing of rapidly changing nonverbal perceptual information. The evidence for causality between temporal processing and reading is far from unequivocal at the moment, however. The distributions of dyslexic and normal readers' temporal acuities, independently of the modality investigated, overlap (e.g., Kinsbourne, Rufo, Gamzu, Palmer, \& Berliner, 1991; May, Williams, \& Dunlap, 1988). A similar overlap has also been reported for children with specific language impairment (SLI) and normal language development (Bishop, Carlyon, Deeks, \& Bishop, 1999). Moreover, reported correlations between temporal acuity and language processing or reading are not perfect (Ahissar, Protopapas, Reid, \& Merzenich, 2000; Au \& Lovegrove, 2001; Brannan \& Williams, 1988; Farmer \& Klein, 1993; Kinsbourne et al., 1991; Tallal, 1980). Therefore, poor temporal acuity alone has not been shown to be sufficient for predicting dyslexia in an individual.

The assumed temporal processing impairment in developmental dyslexia may appear in different tasks as well as across modalities. These possible generalizations were investigated in the present study.

A frequently used method for studying temporal acuity of rapidly presented sequential stimuli is the temporal order judgment (TOJ) task. In this method, the ability to perceive and retain the temporal order of at least two perceptual events is investigated (Brannan \& Williams, 1988; Kinsbourne et al., 1991; May et al., 1988; Mody et al., 1997; Reed, 1989; Tallal, 1980). We compared the TOJ method with another method of temporal acuity assessment, which has been recently applied to dyslexia research (Laasonen, Tomma-Halme, Lahti-Nuuttila, Service, \& Virsu, 2000). This method, estimating what we call temporal processing acuity (TPA), is based on the estimation of simultaneity or nonsimultaneity of brief stimuli in two parallel trains. It does not require the judgment of order.

A pansensory temporal processing deficit has been proposed to be associated with both specific language impairment (SLI; Poppen, Stark, Eisenson, Forrest, \& Wertheim, 1969; Tallal, Stark, Kallman, \& Mellits, 1981) and developmental dyslexia (Galaburda \& Livingstone, 1993; Laasonen et al., 2000; Living stone et al., 1991; Lovegrove, 1993; Stein \& Walsh, 1997). Furthermore, this impairment appears to be more general than merely the impaired perception of order (Farmer \& Klein, 1995). Aphasic adults (Efron, 1963) and "aphasoid" children (Lowe \& Campbell, 1965) have been shown to have difficulties in the temporal ordering of auditory stimuli. Tallal and Piercy (1973a, 1973b) showed that SLI children are impaired in assessing the temporal order structure of brief nonverbal auditory stimuli, both when asked to make sameldifferent discriminations and when asked to make explicit order replications. Tallal (1980) and other investigators (e.g., Reed, 1989) have also found the processing of rapid stimulus sequences to be impaired in developmentally dyslexic children. Group differences in the auditory modality have also been observed in both adolescents (Farmer \& Klein, 1993) and adults (Ahissar et al., 2000; Kinsbourne et al., 1991) with developmental reading difficulties.

In the visual modality, results with SLI children (Tallal \& Piercy, 1973b; Tallal et al., 1981) suggest that at least younger children, 5-6 years old, have difficulties in assessing the order structure of nonverbal visual stimuli. The differences observed by Tallal and Piercy (1973b) were not significant, however. Again, developmentally dyslexic readers have been shown to have difficulties similar to those of participants with SLI, both as children (Brannan \& Williams, 1988; May et al., 1988) and as young adults (Kinsbourne et al., 1991). However, other studies have failed to show statistically significant differences between dyslexic and normal readers in visual temporal acuity (Laasonen et al., 2000; Reed, 1989).

Tactile temporal acuity has been studied less, but impaired processing of the temporal order of brief stimuli has been observed in children with SLI (Tallal, Miller, \& Fitch, 1993; Tallal, Stark, \& Mellits, 1985). In our study of 8- to 12-year-old children (Laasonen et al., 2000), we found developmentally dyslexic children to be inferior to normal children in the estimation of simultaneity or nonsimultaneity of tactile stimulus trains.

At present, one open question is whether impaired temporal processing is similarly related to developmental dyslexia across orthographical systems and ages. Temporal acuity impairment, in both the auditory system and the visual system, has been found to correlate with various tasks of phonological processing, or reading and spelling accuracy and speed. This has been observed in English-speaking children and adults (Ahissar et al., 2000; Brannan \& Williams, 1988; Farmer \& Klein, 1993; Kinsbourne et al., 1991; Tallal, 1980). In languages in which letters and sounds have highly consistent correspondences, impairment of temporal processing and its possible pansensory generalization in reading problems requires more study. The orthography in Finnish is shallow both ways, which means that every phoneme in the language has one corresponding letter (in one case, a combination of two letters), and every letter has only one pronunciation. In this type of orthography, the problem of becoming aware of the phonemic units of language is substantially easier than in languages such as English, in which letter-sound relationships are ambiguous as a rule. Because of this, learning to read and spell is relatively easy. In these languages, developmental dyslexia manifests itself in slower learning and in slower, as well as more error-prone, ultimate reading performance (Wimmer, Landerl, \& Frith, 1999). However, even people with dyslexia become phonologically aware and learn to read and spell pseudowords, in most cases.

One hypothesis in the dyslexia literature (Tallal, 1980) has claimed that a temporal processing deficit causes phoneme representations to remain vague in dyslexic 
readers, which in turn affects reading performance. If this is true, reading in a transparent orthography can be thought of as rehabilitative activity in itself. The letters should anchor possibly vague phoneme representations to the appropriate phonemic categories. We studied welleducated adult-age people with developmental dyslexia, who should have had a fair amount of experience of reading. It could be thought that the effects of a possible temporal processing deficit on phoneme representations in them would have been reduced, or even abolished, by their reading experience. On this account, we would therefore not expect a strong correlation between their performance in temporal processing tasks and phonological tasks. Our battery of reading-related tasks used to screen the dyslexic participants included a phonological awareness task known to be sensitive to differences in reading ability still in adolescent age in Finnish (phonological synthesis) as well as a simple phonological discrimination task and two tests of phonological short-term memory (digit span forward and nonword span). This enabled us to inspect the relationship between temporal processing ability and phonological processing in our results.

Lately, several studies of temporal processing in dyslexia in Finnish have been reported. In a previous study in our laboratory, we found that developmentally dyslexic children were somewhat impaired in temporal acuity tasks in all sensory modalities investigated, relative to their agematched controls (Laasonen et al., 2000). Other Finnish studies (Hari \& Kiesilä, 1996; Hari et al., 2001; Hari, Valta, \& Uutela, 1999; Helenius, Uutela, \& Hari, 1999; Kujala et al., 2000) have found impaired processing of rapid auditory and visual sequences in adult dyslexics, but these studies did not include multiple modality comparisons.

In the present study, we investigated temporal acuity and its generalization over perceptual modalities and assessment methods in adult Finnish dyslexics. If temporal processing deficits are related to developmental dyslexia, the deficits should also be found in well-educated dyslexics whose learning problems have been limited to reading difficulties. Therefore, the participants were well-educated adults, and their average intelligence was normal or above. We used two assessment methods in tactile, auditory, and visual perceptual systems. One method required TOJs, and the other method required comparison of simultaneous or nonsimultaneous pulses in stimulus trains (temporal processing acuity, TPA). Both methods were used to find thresholds for correct judgments when pulse interval was varied. The participants were also tested on a battery of reading-related tasks. We found that, as a group, the dyslexic readers suffered from a generalized impairment of temporal acuity, with emphasis on auditory and tactile difficulties. However, the extensive overlap between the groups prevented reliable individual prediction of dyslexia individually from temporal acuity measures. The impairment was not confined to order perception; it appeared with both methods. Temporal acuity impairment, found by either method, was found to be related to a measure of phonological awareness. Dyslexic readers were not infe- rior to normal readers in the nontemporal aspects of our psychophysical tasks.

\section{METHOD}

\section{Participants}

Sixteen participants with developmental dyslexia (20-36 years old; 12 females, 4 males) and 16 control participants (20-36 years old; 9 females, 7 males), all volunteers, participated in this study. The participants were recruited through advertisements at the University of Helsinki and in a newsletter of a local dyslexia association. In the dyslexia group, there were 9 university students; in the control group, there were 10 university students. The demographic characteristics of the participants and their performance in WAIS-R are presented in Table 1 . The groups did not differ statistically signif icantly in age $[t(30)=0.99, p<.34]$, duration of education $[t(24.69)=1.45, p<.16]$, or $\operatorname{sex}\left[\chi^{2}(1, N=32)=1.25, p<.27\right]$. No participant had a history of neurological disorders. All the participants performed at least at the level of average ability (IQ $>86$ ), and the groups did not differ statistically significantly in their WAIS-R (Wechsler, 1992) verbal IQ $[t(30)=1.43, p<.17$, power $=0.29]$, performance IQ $[t(30)=1.99, p<.06$, power $=0.48]$, or full IQ $[t(30)=1.91, p<.07$, power $=0.45]$. Dyslexic readers performed significantly worse in two single subtests only [digit span, $t(30)=3.11, p<.005$; picture arrangement, $t(30)=2.10, p<$ .05]. Verbal span differences have been found in a large number of studies comparing dyslexic and normal readers (e.g., Shankweiler, Liberman, Mark, Fowler, \& Fischer, 1979; see also Snowling, 2000, for a review).

To verify reading impairment, the participants had to report a history of dyslexic difficulties. Eleven participants had a formal diagnosis made by a clinical psychologist or a speech therapist. The remaining 5 participants reported a consistent history of difficulties in reading and writing. To be included in the group of dyslexic readers, a participant had to perform at least 1 standard deviation $(S D)$ below the controls' mean in at least three reading-related tasks. Fourteen participants had slow reading speed; 8 participants had impaired phonological processing. However, the reading-related tasks listed below were all included in diagnosing participants, since there are no standardized measures in Finnish for defining reading level in adult readers. Furthermore, with the Finnish shallow orthography, certain tasks, such as nonword reading, do not clearly differentiate between dyslexic and normal readers (Harris \& Hatano, 1999).

\section{Neuropsychological Assessment}

Wechsler Memory Scale-Revised (WMS-R): Associative learning. To assess verbal memory functions, we administered the associative learning test of the WMS-R (Wechsler, 1997). In this task, the participant was read aloud eight pairs of words to memorize. After reading the list, the experimenter read the first word in each pair in turn, and the participant was asked to say aloud its pair. Half of the pairs associated easily (e.g., eye-ear); half were harder to memorize (e.g., pony-telephone). The list was presented three times by the experimenter and recalled each time by the participant. The total number of correctly recalled words was recorded.

Reading-related tasks. Phonological discrimination was assessed with a 12-pair list of three-syllable sequence pairs (e.g., /keteke/-/kedeke/). The participant heard one pair at a time from a tape recorder and assessed whether the sequences were similar or differed according to one phoneme. Number of correct answers was recorded.

In phonological synthesis, the participant heard separate phonemes from the tape recorder and was asked to name the word that was composed of the individual phonemes (e.g., the participant heard the Finnish phonemes /p/, /a/, /1/, /1/, and /o/ and named the word pallo $[$ ball $])$. The number of correct answers was recorded. 
Table 1

Demographic Variables of the Participants

\begin{tabular}{|c|c|c|c|c|c|c|c|c|c|c|c|c|c|c|c|c|}
\hline \multirow[b]{2}{*}{ Group } & \multirow{2}{*}{$\begin{array}{c}\text { Age } \\
\text { (Years) }\end{array}$} & \multirow{2}{*}{$\begin{array}{c}\text { Education } \\
\text { (Years) }\end{array}$} & \multicolumn{14}{|c|}{ WAIS-R } \\
\hline & & & $\mathrm{I}$ & Span & $\mathrm{V}$ & $\mathrm{A}$ & $\mathrm{C}$ & Sim & $\mathrm{PC}$ & $\mathrm{PA}$ & $\mathrm{BD}$ & $\mathrm{OA}$ & DS & VIQ & PIQ & $\overline{\text { FIQ }}$ \\
\hline \multicolumn{17}{|c|}{ Dyslexic readers } \\
\hline$M$ & 26.94 & 14.78 & 11.75 & 9.50 & 11.38 & 11.75 & 12.31 & 12.13 & 11.38 & 11.38 & 12.13 & 12.19 & 11.31 & 107.25 & 109.38 & 109.06 \\
\hline$S D$ & 5.31 & 1.96 & 2.02 & 1.67 & 2.03 & 2.67 & 1.25 & 2.00 & 1.93 & 2.45 & 2.60 & 2.20 & 2.82 & 9.10 & 11.00 & 8.68 \\
\hline \multicolumn{17}{|c|}{ Normal readers } \\
\hline$M$ & 25.13 & 15.47 & 13.06 & 11.88 & 12.00 & 12.50 & 12.00 & 11.69 & 12.38 & 13.19 & 12.69 & 12.56 & 12.94 & 112.19 & 116.44 & 115.13 \\
\hline$S D$ & 5.07 & 2.72 & 1.88 & 2.55 & 1.83 & 2.73 & 2.34 & 3.03 & 2.50 & 2.43 & 2.21 & 2.80 & 2.49 & 10.40 & 9.03 & 9.26 \\
\hline
\end{tabular}

Note-WAIS-R, Wechsler Adult Intelligence Scale-Revised; I, information; Span, digit span; A, arithmetic; C, comprehension; Sim, similarities; PC, picture completion; PA, picture arrangement; BD, block design; OA, object assembly; DS, digit symbol; VIQ, verbal scale intelligence quotient; PIQ, performance scale intelligence quotient; FIQ, full scale intelligence quotient.

Naming speed was assessed using the rapid alternating stimulus naming (RAS) task. The participants named as fast as possible a 50-item matrix of numbers, letters, and colors (Wolf, 1986). Time in seconds was recorded. The task was administered twice, and the results of the second trial were used in the analyses.

Reading speed was evaluated with a text, which the participant read aloud as fast as possible for $1 \mathrm{~min}$. Number of words read in $1 \mathrm{~min}$ was recorded.

For lexical decision, we used a computerized task that assessed the speed at which the participant made the decision of whether or not a displayed string of four to six letters was a real Finnish word. The task included 141 trials, which began with a cue: a cross was presented for $500 \mathrm{msec}$ in the middle of a computer screen (Power Macintosh 7500 , Apple 15-in. monitor). A priming word appeared immediately for $200 \mathrm{msec}$ at the indicated location. It was either semantically related to the next word or not. The second word, presented immediately until a response was given, was the target for lexical decision. It was either covered or uncovered by a grating (mask occurrence probability $=.5$ ), but the task was always to make a decision, as quickly as possible, whether the second letter string was a word or a nonword as a yes/no response. The participants responded by pressing one key in a standard keyboard for "word" (the "M" key) and another for "nonword" (the "C" key). Reaction times (RTs) for the target words were recorded after the exclusion of incorrect answers and deviant latencies (more than 2 SDs above or below the mean RT).

Word segmentation speed was assessed with a 78-item list that consisted of strings of two to four conjoint words (Lindeman, 1998). The participant had to mark as many word boundaries in each string as possible in $3 \mathrm{~min}$ (e.g., vastatatarjota, correct segmentation would be vastata|tarjota [in English, answeroffer, and correct segmentation would be answer|offer]). The number of correct segmentations was recorded.

Reading comprehension was evaluated using two texts, one fiction and one factual. The participant read one text at a time and answered multiple-choice questions assessing comprehension of details/ facts, words/phrases, cause-result/order, main idea/meaning, and ability to draw conclusions/make interpretations (Lindeman, 1998). No time constraints were applied, and the participants could read the text as many times as they wanted. The number of correct answers was recorded.

Letter rotation was assessed with a computerized task. The participant had to evaluate whether a displayed tilted letter (uppercase F, L, or R) was correct or a mirror image. The task included 84 trials, in which the target letter appeared in the middle of the screen and was presented until a correct response was given. The participant was advised to press the space bar on the keyboard for answering "correct" and the "B" key for answering "mirror." The rotation angle of the letters varied between $0^{\circ}$ and $180^{\circ}$ to the left and right (with $30^{\circ}$ steps, 12-14 trials with each angle). RTs were calculated after exclusion of incorrect answers and deviant latencies (more than 2 SDs above or below the mean RT).
Nonword span was evaluated with lengthening sequences of consonant-vowel-consonant-vowel (CVCV) nonwords. The participant heard the sequences from a tape recorder and repeated them back (e.g., /potu-hine/, /sile-hine-tepa/). Five sequences were presented at each length. The length of span (longest sequence of four-phoneme nonwords repeated correctly on at least one attempt) was recorded.

\section{Temporal Order Judgment (TOJ)}

The experimental setup and stimulus presentation are shown in Figure 1A. TOJ was assessed in three modalities (tactile, auditory, and visual). Stimulus pairs were indentations of the index and middle fingertips in the tactile task, sounds of different pitches in the auditory task, and light flashes from two sources in the visual task. In each task, the participant was instructed to estimate which one of the two stimulus pulses occurred first.

Temporal intervals were varied using a computer-controlled apparatus built for this purpose; the driver pulse accuracy of the apparatus was at microsecond level. The two stimulus pulses of TOJ (A and B) were never simultaneous or overlapping, and each stimulus pulse was clearly perceived and identified as a separate perceptual event. The participant responded by pushing one button of a response device for "A first" presentation and another one for "B first" presentation. The probability of "A first" was .5. The next stimulus followed each response after $0.3-0.5 \mathrm{sec}$ without any explicit feedback on the correctness of the response. Responses were not speeded in any manner, and the participant was advised to try to respond as accurately as possible. If the participant reported false responses, the task was commenced again from the beginning. All the participants could master the tasks. The order of the tasks for 8 participants in each group was tactileauditory-visual and was the reverse for the other 8 participants.

The adaptive transformed up-and-down threshold search method of Wetherill and Levitt (1965) was used to estimate the stimulus onset asynchrony (SOA, in milliseconds) required for probability .84 of correct choices in our yes/no judgments. When the interval between stimuli was long, the task was easy; when the SOA decreased, performance eventually became random. If the participants were not sure of the answer, they were instructed to guess the correct alternative. The SOA of the stimuli at the beginning of each task was $500 \mathrm{msec}$. If the participants correctly assessed the order of pulses, SOA decreased $0.05 \log$ units after each response. Following the first incorrect answer, SOA increased $0.05 \log$ units. After this first reversal, the SOA decreased only after a sequence of four successive correct choices and otherwise increased after every incorrect answer by the amount mentioned above. The first two reversals were discarded, and the average of 12 reversals after these provided an estimate of the $84 \%$ correct threshold. The presentation of stimuli and collection of data were computerized.

In the tactile TOJ task, the participant received two brief indentations, one to the tip of the left-hand middle finger and another one to the tip of the left-hand index finger. The task was to judge which indentation occurred first. The indentations of the skin were produced 
A

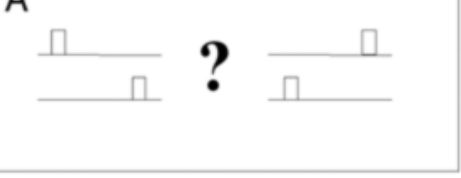

B

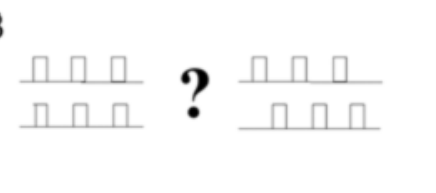

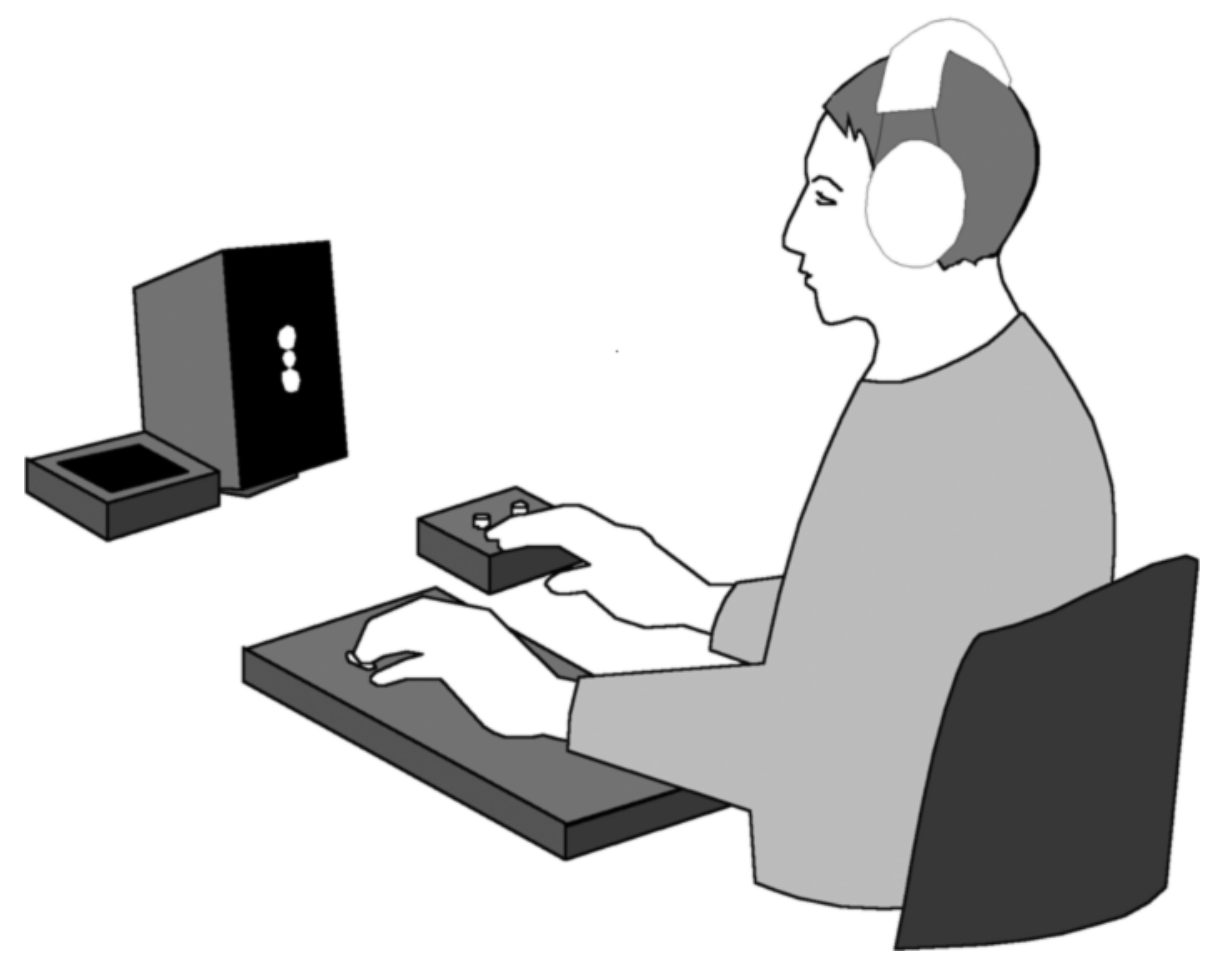

Figure 1. Setup of experiments. A participant performing the tactile task is depicted as an example in the figure. In the TOJ method, the participant judged which of two pulse stimuli, each on a different channel, as on one of two fingertips, was presented first (Panel A). In the TPA method, the participant judged whether or not the stimulus pulses of the two channels, presented now as two parallel trains, were simultaneous (Panel B). The participants indicated their judgments by pressing a button.

by the blunt tips of solenoid axes touching the skin. The driving pulse of the solenoids was $8 \mathrm{msec}$ at $20 \mathrm{~V}$. The force of an indentation was approximately $0.9 \mathrm{~N}$ (maximum mass lifted then was about $92 \mathrm{~g}$ ), and the maximum amplitude was $2 \mathrm{~mm}$. The solenoids were embedded in a soft padding, which attenuated their sound; the participant used headphones, which attenuated the sound a further $30 \mathrm{~dB}$, so that, at the peak, the clicking solenoid noise at the participant's ear canal entrance was about $35 \mathrm{~dB}$ SPL.

In the auditory TOJ task, the participant assessed which one of the two 8-msec tone bursts ("high" or "low") was presented first. The stimuli of this task were complicated because the same pulse stimuli were used in the TPA experiments, in which various artifacts (e.g., different perceptual quality as an unwanted cue of simultaneous presentations) had to be avoided. In order to minimize burst duration without sacrificing stimulus pulse identifiability and intensity, tone bursts were produced by gating function generator sine waves so that they had zero-phase onsets and offsets without smoothing. The frequencies of the sine waves were 750,1625 , or $3625 \mathrm{~Hz}$. In spite of spectral splatter, these frequencies produced clearly different and identifiable pitches that did not combine to elements of traditional chords and did not fuse to a single perception at the SOAs required by the experiments. The two tone bursts presented for order judgments always had different pitches. This resulted in three pitch combinations and six presentation possibilities altogether. All participants were able to perform the experiment reliably, at least at long SOAs. Subjectively, the tone bursts had approximately equal loudness. Their sound pressure levels measured at the participant's ears were about $70 \mathrm{~dB}$ SPL for continuous tones. The participant was seated $90 \mathrm{~cm}$ from the loudspeaker through which the tones were presented.

In the visual TOJ task, the participant estimated whether an upper or lower 8-msec flash of light of central vision occurred first. The participant was seated $90 \mathrm{~cm}$ from a matte black box $(18.5 \times 8 \mathrm{~cm})$ in which two green (565-nm) diffused light-emitting diodes (LEDs) were implanted, one $5 \mathrm{~mm}$ above the other (Figure 1). The LEDs were $8 \mathrm{~mm}$ in diameter, subtending $0.5^{\circ}$ of visual angle. The luminance of flashes was about $4 \mathrm{~cd} / \mathrm{m}^{2}$, and the luminance of the background was $1.5 \mathrm{~cd} / \mathrm{m}^{2}$. The participant fixated a constantly lit green LED (3 mm in diameter) between the flashed stimulus LEDs. In general, no apparent movement was seen as the constantly lit fixation LED was inserted between the flashing stimulus LEDs.

\section{Temporal Processing Acuity (TPA)}

For determining the TPA, the phase-difference detection method (Virsu, 1997), as illustrated in Figure 1B, was used. Two identical 
trains of brief stimuli (A and B) consisted of three stimulus pulses at constant time intervals. The trains were delivered in parallel (simultaneously or almost simultaneously) using the same two perceptual channels as in TOJ. The stimulus pulses were the same as in the TOJ method. The train frequency of A and B was always the same within one trial, but it varied between trials as determined by the Wetherill and Levitt (1965) algorithm used in TOJ. The phase identity or difference of Trains A and B, which was to be detected on different trials, varied randomly with a probability of .5-that is, the pulses of A and $\mathrm{B}$ were either simultaneous (Trains A and B in the same phase) or nonsimultaneous $\left(180^{\circ}\right.$ phase shift between the trains). Which pulse train was leading in the counterphase presentation (A or B) varied randomly with a probability of .5 .

The participants were instructed to judge, after each stimulus presentation, whether or not the pulses of the two channels were simultaneous. They indicated their judgments by pushing one button on a response device for simultaneous pulses and another one for nonsimultaneous pulses. The task was easy at low frequencies at which the temporal distances (SOAs) between pulses were long, and the responses became random at high frequencies when SOAs were short. The threshold SOA (in milliseconds) was between these two cases. Because the duration of all stimulus pulses was the same $8 \mathrm{msec}$, the onset and offset times were also always the same. Thus, the interpulse interval was always the same within a stimulus train.

The same procedure and adaptive method as for TOJ, with the same parameter values, were used for estimating TPAs as $84 \%$ correct thresholds. At the beginning of acuity estimation, one stimulus pulse per second was delivered in each pulse triplet of each channel (e.g., each finger). That is, the SOA of stimulus pulses within each separate triplet was $1,000 \mathrm{msec}$, but the SOA between the pulses of different channels depended on whether or not the pulses were simultaneous. When the stimulus pulses of the parallel triplets were simultaneous, their SOA was zero. When the pulses were nonsimultaneous (trains out of phase), the SOA difference between the pulses of the triplets of different channels was $500 \mathrm{msec}$ at the beginning. So, half a period corresponded to the SOA that was measured in TOJ. Temporal acuity is understood to increase when the threshold SOA of TOJ or TPA decreases.

In the tactile TPA task, the participant judged whether or not the indentations of the index finger and the middle finger occurred simultaneously when the three 8-msec indentations were delivered to the fingertips of the left hand. One additional masking solenoid acted in counterphase on each perceptual channel in the TPA determination. Its purpose was to make the sound cues remaining after loudness attenuation entirely noninformative regarding the phase of the tactile stimulus presentation. It was not possible to mask the clicks with a moderately loud noise. In the auditory TPA task, the participant judged whether or not the three 8-msec tone bursts of the two parallel trains were simultaneous. The tone bursts of each train had the same pitch, and the two trains differed in the pitch of their tone bursts. This resulted in the same six presentation alternatives as in TOJ. In the visual TPA task, the participant estimated whether or not the three flashes of light in each of the two LEDs were simultaneous.

The pulses were presented as trains for simultaneity or nonsimultaneity judgments and not as pulse pairs for order judgments. It was not expected that our inexperienced participants would have been able to estimate the simultaneity or nonsimultaneity of two pulses without judging their temporal order, and, therefore, a three-pulse sequence was applied. Three pulses per channel fulfills the requirement of periodicity for phase detection and yields a genuine successiveness for stimuli, but it does not lead to unreasonable trial durations.

The possibility that the participants used the first or last pulses of the two pulse trains as cues of simultaneity or nonsimultaneity judgments was considered. This cue is obvious at low train frequencies (long SOAs); therefore, we used mask pulses and approximately constant stimulation durations in our earlier studies to exclude the use of onset and offset cues (Laasonen et al., 2000; Virsu, 1997). The results of these and control experiments, as well as the differences between the results obtained with the TOJ and TPA methods, suggested that the onset and offset cues of stimulus sequences cannot be utilized near the threshold, although the onset and offset are obvious as phase cues at low suprathreshold frequencies. We also have tried to remove all irrelevant cues based on fusion, stereo/mono distinction, stimulus length, energy, modality, apparent movement, and so on as possible means for responding correctly without the intended temporal phase detection.

The participants' task was to judge or guess, after each stimulus presentation, the physically correct response as well as possible also when they were unsure of the correct answer. The participants were not instructed to use a single criterion, either simultaneity or nonsimultaneity, which could have biased decision making, but were instructed to monitor both at the same time in an unbiased way in our yes/no setting. Since all single trials were recorded for later offline analyses, we were able to check afterward how unbiased the responses of each participant had actually been. For example, if a participant preferred "simultaneous" responses at SOAs clearly shorter than threshold, the participant would respond correctly to in-phase stimulus trains but incorrectly to out-of-phase trains.

The response probability curves of all participants ( 480 plots altogether) were classified visually. The inspection showed that, in spite of the same instruction and order balancing, response biases varied between tasks, but this variation was similar in the dyslexia and control groups. There was no response bias depending on which stimulus train (A or B) was the first, when the trains were out of phase. The responses of a participant were classified as unbiased when there was at least one clearly incorrect response to both in-phase and out-of-phase pulse trains. In the tactile TPA task, of the participants in the dyslexia and control groups, respectively, 7 and 10 were unbiased, 8 and 6 preferred nonsimultaneity, and 1 and 0 preferred simultaneity. In the auditory TPA task, the corresponding numbers were 14 and 14, 1 and 1, and 1 and 1 . In the visual TPA task, the numbers were 5 and 9,11 and 7 , and 0 and 0 .

\section{Statistical Analyses}

The distributional properties of the variables were studied. All variables, including their logarithmic and $z$-standard score transformations, were inspected regarding outliers and were tested for normality and homogeneity of variances. Statistical analyses were carried out on the original untransformed data, because the corrections employed in some cases did not essentially change the results of the analyses. Overall group differences were tested with multivariate analyses of variance (MANOVA) and mixed analyses of variance (ANOVA). Since we hypothesized a priori that the dyslexic readers would perform more poorly than their controls (Farmer \& Klein, 1995; Tallal, Galaburda, et al., 1993; Tallal et al., 1998), group differences in individual tasks were analyzed with one-tailed $t$ tests (corrected for unequal variances when required). Two-tailed $t$-test $p$ values are reported in all other cases. The significance level was .05. Discriminant analysis based on the temporal acuity measures was computed for classifying the participants. Pearson product-moment correlations were computed for logarithmically transformed variables to achieve improved linearity and homogeneity of variability. Variables were transformed so that larger values indicate better performance (sign change when needed). Principal component analyses were based on transformed variables. Scree plots of eigenvalues (at least 1 in accepted factors) and assessment of the percentage of total variation explained (over 60\%) were used to determine the optimal number of components to extract.

\section{RESULTS}

\section{Group Differences in Reading-Related Tasks}

The dyslexic and normal readers' performance in reading-related tasks is presented in Table 2 . The dyslexic readers performed less well than did the controls in 
Table 2

Dyslexic Readers' $(n=16)$ and Normal Readers' $(n=16)$ Performance in Reading-Related Tasks

\begin{tabular}{|c|c|c|c|c|c|}
\hline Task & Group & $M$ & Min & $\operatorname{Max}$ & $S D$ \\
\hline \multirow[t]{2}{*}{ Phonological discrimination (correct answers)* } & Dyslexic & 10.06 & 8 & 12 & 1.06 \\
\hline & Control & 10.69 & 9 & 11 & 0.60 \\
\hline \multirow[t]{2}{*}{ Phonological synthesis (correct answers)* } & Dyslexic & 8.50 & 5 & 10 & 1.51 \\
\hline & Control & 9.50 & 8 & 10 & 0.73 \\
\hline \multirow[t]{2}{*}{ Letter rotation (reaction time in seconds) } & Dyslexic & $1,209.63$ & 768 & 1,899 & 331.97 \\
\hline & Control & $1,069.88$ & 796 & 1,761 & 280.37 \\
\hline \multirow[t]{2}{*}{ Lexical decision (reaction time in seconds)* } & Dyslexic & 901.50 & 571 & 1,370 & 235.73 \\
\hline & Control & 637.25 & 543 & 795 & 72.09 \\
\hline \multirow[t]{2}{*}{ Naming speed-RAS (time in seconds)* } & Dyslexic & 29.81 & 18 & 55 & 8.63 \\
\hline & Control & 23.50 & 19 & 28 & 2.99 \\
\hline \multirow[t]{2}{*}{ Word segmentation speed (correct answers)* } & Dyslexic & 138.63 & 30 & 214 & 52.05 \\
\hline & Control & 200.06 & 118 & 214 & 31.80 \\
\hline \multirow[t]{2}{*}{ Reading speed (words read/1 min)* } & Dyslexic & 113.00 & 42 & 169 & 28.05 \\
\hline & Control & 152.31 & 118 & 196 & 23.09 \\
\hline \multirow[t]{2}{*}{ Reading comprehension-fact (correct)* } & Dyslexic & 9.50 & 5 & 12 & 1.86 \\
\hline & Control & 11.25 & 10 & 12 & 0.58 \\
\hline \multirow[t]{2}{*}{ Reading comprehension-fiction (correct) } & Dyslexic & 9.31 & 6 & 11 & 1.40 \\
\hline & Control & 9.88 & 9 & 11 & 0.50 \\
\hline \multirow[t]{2}{*}{ Nonword span (span length)* } & Dyslexic & 3.69 & 3 & 5 & 0.60 \\
\hline & Control & 4.63 & 4 & 6 & 0.62 \\
\hline \multirow[t]{2}{*}{ WAIS-R digit span forward (span length)* } & Dyslexic & 5.69 & 4 & 7 & 0.79 \\
\hline & Control & 6.88 & 6 & 8 & 0.89 \\
\hline \multirow[t]{2}{*}{ WAIS-R digit span backward (span length)* } & Dyslexic & 4.75 & 4 & 6 & 0.58 \\
\hline & Control & 5.63 & 4 & 8 & 1.02 \\
\hline \multirow[t]{2}{*}{ WMS-R associative learning (correct) } & Dyslexic & 17.06 & 9 & 24 & 5.34 \\
\hline & Control & 19.56 & 12 & 24 & 3.98 \\
\hline
\end{tabular}

$* p<.05$, two-tailed $t$ tests.

every task. The difference in reading- and spelling-related task performance was statistically significant when tested with $2 \times 13$ MANOVA (Group $\times$ Task) $[F(13,18)=3.88$, $p<.005]$. In two-tailed group comparisons, the difference between the dyslexic and normal readers' means was statistically significant, the dyslexic readers' performance being significantly poorer in all other tasks, except "letter rotation" $\mathrm{RT}[t(30)=1.29, p<.21]$, "reading comprehension-fiction" score $[t(18.76)=1.51, p<$ $.15]$, and "associative learning" subtest score of WMS-R $[t(27.76)=1.50, p<.15]$. Although the dyslexic and normal readers differed in time-constrained tasks, we could not find differences in their error rates [letter rotation, $t(30)=0.21, p<.84$; lexical decision, $t(30)=0.64$, $p<.53$; naming, $t(15)=1.38, p<.19$; word segmentation, $t(15)=1.39, p<.19$ ], except in reading speed $[t(19.39)=2.45, p<.03]$.

\section{Group Differences in Temporal Acuity and Threshold Variation}

The $84 \%$ correct thresholds of TOJ and TPA in different tasks and modalities are presented in Figure 2. In general, the average temporal acuity of the dyslexic readers was poorer than that of the normal readers. The results were analyzed with a three-way mixed ANOVA, in which reading group (dyslexia, control) was a between-subjects factor and method (TOJ/TPA) and modality (tactile, auditory, visual) were within-subjects factors of a $2 \times 2 \times 3$ design. The temporal acuity of the dyslexia group differed statistically significantly from that of the control group $[F(1,30)=6.05, p<.02$, power $=.66]$. Also, the main effects of method $[F(1,30)=22.48, p<.0001$, power $=$ $1]$ and modality $[F(2,60)=53.30, p<.0001$, power $=1]$ were significant. The dyslexic and normal readers' average acuity differed depending on the method or modality, as indicated by the statistically significant interactions between group and method $[F(1,30)=4.71, p<.04$, power $=.55]$ and group and modality $[F(2,60)=3.36$, $p<.05$, power $=.61]$. The interaction of group $\times$ method $\times$ modality was not significant $[F(2,60)=2.43$, $p<.10$, power $=.46$ ] .

The significance of interactions indicated that the effects of different methods and modalities should be studied separately. In TOJ (Figure 2A), a trend for a statistically significant interaction between group and modality appeared $[F(2,60)=3.10, p<.053$, power $=.57 ; p<$ .066 , with Greenhouse-Geisser correction for correlations]. The normal readers and the dyslexic readers required, on average, 29-msec and 34-msec SOA, respectively, for judging the order of flashes in vision, but the difference was not statistically significant $[t(30)=1.24$, $p<.12$, power $=.34]$. In contrast, the other two group differences in TOJ were significant (note asterisks in Figure 2). The SOA thresholds for successfully judging the order of tactile stimuli were 141 and $255 \mathrm{msec}$ for the normal readers and the dyslexic readers, respectively $[t(18.41)=2.46, p<.02$, power $=.73]$. The longest SOAs were required in the auditory TOJ: 215 and $358 \mathrm{msec}$ for the normal readers and the dyslexic readers, respectively $[t(30)=2.00, p<.03$, power $=.60]$.

The dyslexic readers also required longer SOAs in the phase difference detection tasks of TPA than did the nor- 

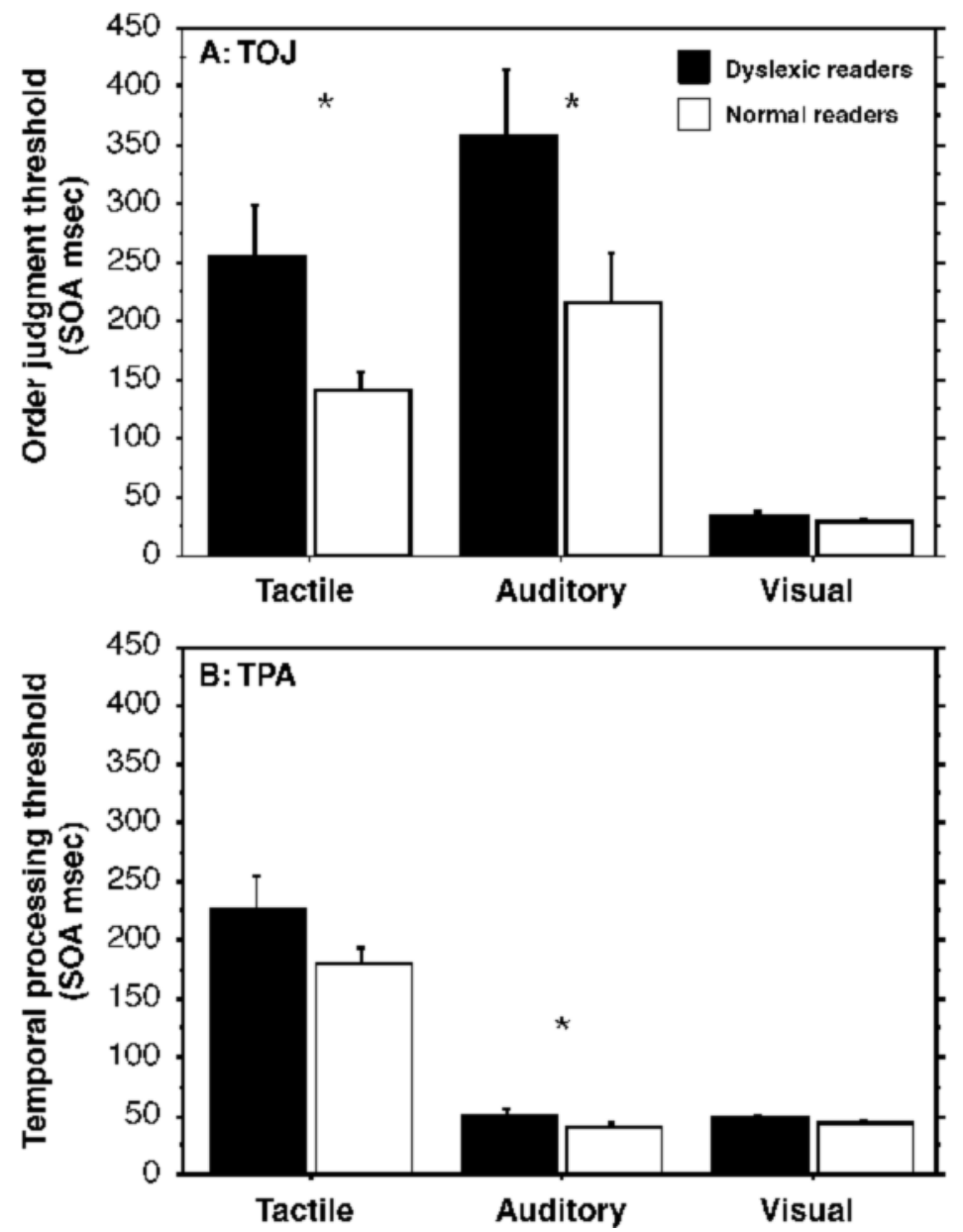

Figure 2. Temporal thresholds of different modalities of TOJ and TPA methods for the dyslexic readers and the normal readers. The bars represent group mean SOAs $(N=16$, in both groups), and error bars indicate 1 standard error of the mean $(S E M)$. Average temporal acuity is better, the lower the score is. Asterisks (*) refer to $p<.05$ of one-tailed $t$ tests.

mal readers (Figure 2B), but the group difference was significant only in the auditory TPA task $[t(30)=1.78, p<$ .04 , power $=.53$ ]. The normal readers required $41 \mathrm{msec}$ to make the auditory assessment of simultaneity or nonsimultaneity of tone bursts. This means that the normal readers were able to distinguish between in-phase and outof-phase brief pulse-like auditory events 12.2 times per second $[1000 /(2 \times 41) \mathrm{Hz}]$ at a $84 \%$ correct level. For the dyslexic readers, the corresponding auditory SOA was $51 \mathrm{msec}$-that is, the poor readers were able to segregate 9.8 auditory events per second. In the visual task, the TPA of the control group was $45 \mathrm{msec}$ (11.1 phase segregations/sec), whereas the corresponding value of the dyslexia group was $49 \mathrm{msec}(10.2$ phase segregations/sec) $[t(30)=1.25, p<.11$, power $=.35]$. The TPA averages in the tactile task were the worst: 179 and $226 \mathrm{msec}$ for the normal and the dyslexic readers, respectively $(2.8$ and 2.2 phase segregations/sec) $[t(22.51)=1.52, p<$ .07 , power $=.44]$.
In the ANOVA of the TPA results, the interaction between group and modality was not significant $[F(2,60)=$ $1.98, p<.15$, power $=.38$ ]. The interaction also was not significant in the TOJ results of the three modalities; therefore, there was no statistically reliable evidence in the TOJ or TPA results separately that group differences in some modalities were clearer than in others, although the overall ANOVA indicated a significant group $\times$ modality interaction when all six tasks were included in the analysis.

The temporal threshold of each participant and task in Figure 2 consists of a mean of 12 reversals: 6 peaks in which the diminishing temporal interval became so short that the participant was not able to produce four consecutive correct responses, and 6 throughs in which the increasing interval became long enough for four consecutive correct responses. If the participant produced incorrect responses due to attentional lapses or carelessness, for example, the reversal points of different up/down runs would 
vary. Such within-subjects variation can be quantified independently of the temporal threshold by computing the coefficient of variation of the averages between each peak and through, six averages altogether in the present temporal thresholds. Thus, the coefficient of variation (CV; standard deviation divided by the mean) describes the accuracy and consistency of the participant's responses during the threshold search. Here, the CV is indicated in percentages. It can be interpreted as an index of how well a participant masters the nontemporal aspects of our temporal acuity experiments.

Figure 3A shows threshold variation for the TOJ method, and Figure 3B shows threshold variation for the TPA method. The results provided no evidence that the dyslexic readers performed worse, relative to the normal readers, in the nontemporal aspects of these psychophysical experiments: Their threshold variation was smaller than that of the normal readers in three tasks and larger in three other tasks. Neither did the groups differ significantly in the threshold variation in any task. A three-way mixed ANOVA resulted in a nonsignificant main effect of reading group $[F(1,30)=0.008, p<.93$, power $=.05]$ and no significant interactions with group as a factor. However, the main effects of assessment method $[F(1,30)=21.25, p<.0001$, power $=1]$, and modality $[F(2,60)=16.77, p<.0001$, power $=1]$ were significant. On the other hand, threshold variation did not affect the temporal acuity differences between the groups in any one of the six tasks when the variation was used as an explanatory factor in simple regression analysis and $t$ tests were computed for the residuals.

\section{Individual Comparisons of Temporal Acuity}

The distributions of temporal acuities of individualparticipants in the two groups overlapped, although the dyslexic readers suffered from impaired temporal acuity on the average. Figure 4 shows the extent of the overlap for
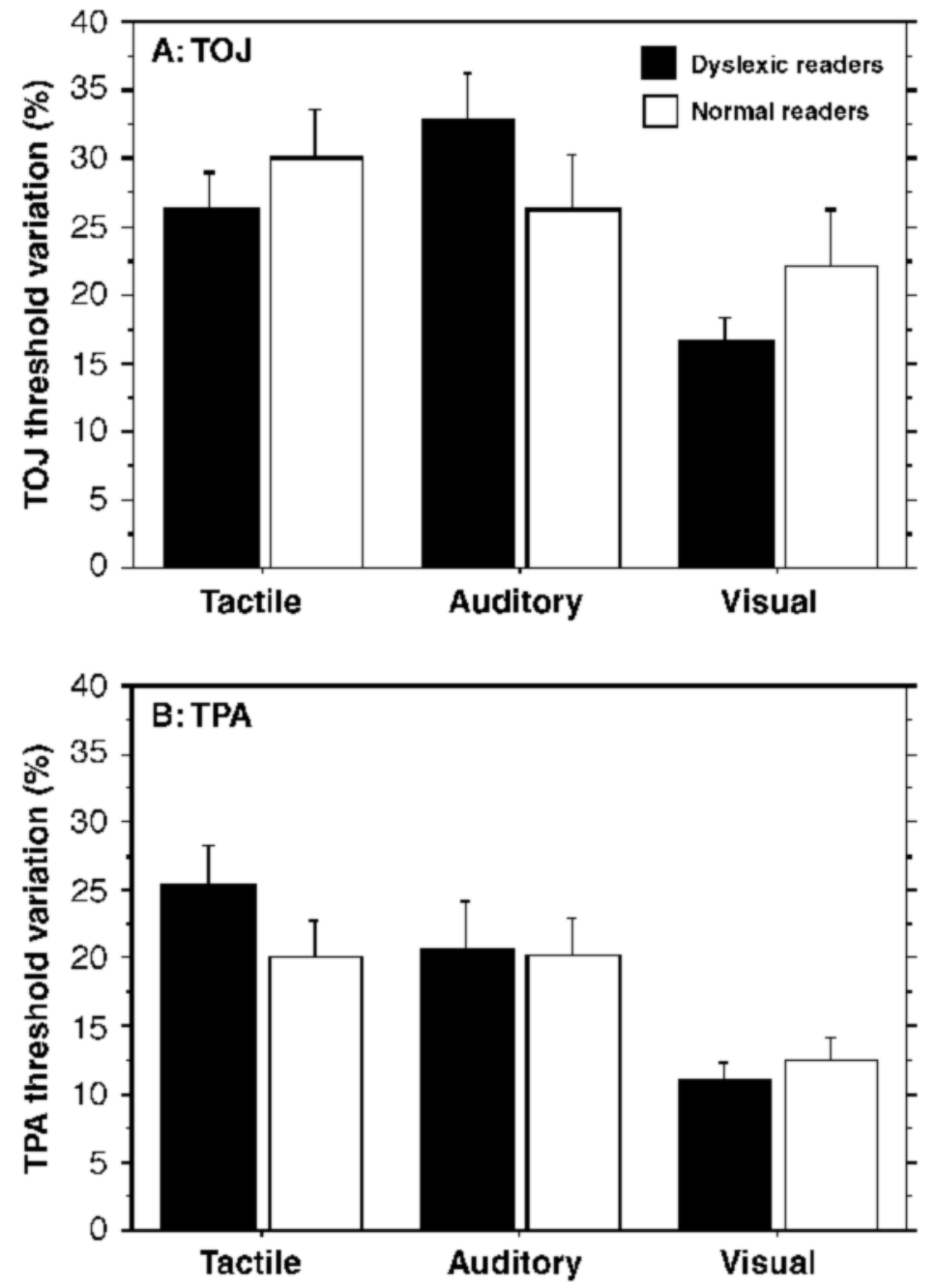

Figure 3. Average within-subjects variation of temporal thresholds of Figure $\mathbf{2}$ in different modalities of TOJ and TPA methods for the dyslexic readers and the normal readers. Other data as in Figure 2. 


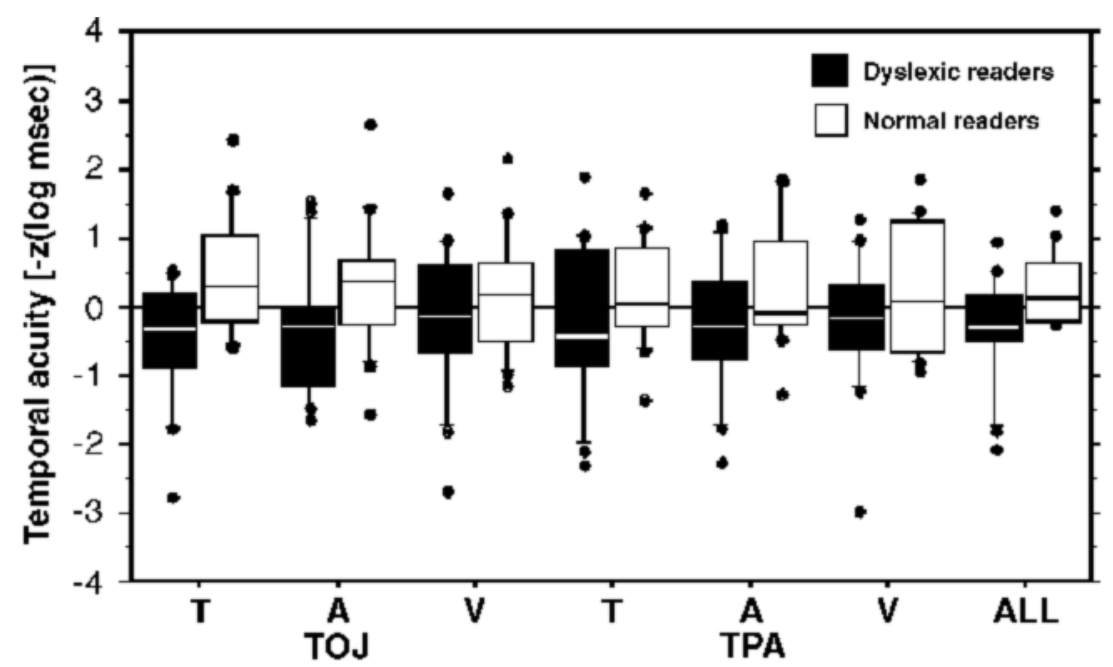

Figure 4. Distribution of temporal acuity of the dyslexic readers and the normal readers estimated from TOJ and TPA tasks and their combination index. The horizontal line in each box represents the median of the group; the box, 25 th to 75 th percentiles; the whiskers, 10 th and 90 th percentiles; and points, values outside these. The acuity thresholds were logarithmically transformed and standardized as $z$ scores over the two groups for compatibility. All variables were inverted, so that larger values indicate better performance.

all six temporal acuity tasks and their combination index (average over all the tasks); the frequency distributions of the dyslexic readers and the normal readers are presented as box plots for variables standardized as $z$ scores over both groups in each task. Like the mean (Figure 2), the median temporal acuity of the dyslexic readers was poorer than that of the normal readers in all comparisons. As an ad hoc classification, discriminant analysis based on the six temporal acuity measures was performed. For the 32 participants of the two groups, the analysis classified 11 participants incorrectly: 4 controls as dyslexics and 7 dyslexics as controls. The classification was not statistically successful ( $p<.38$, in Wilks's Lambda). Thus, it would not have been possible to accurately predict the group membership of single individuals on the basis of temporal acuity results alone. There were normal readers with poorer than median dyslexic temporal acuity, and there were dyslexic readers with better than median normal temporal acuity. Especially in visual tasks, in which group differences were not significant, the overlap was large.

We examined separately those dyslexic readers who had clear temporal acuity impairments in TOJ and TPA tasks. We extracted from the dyslexia group the participants whose temporal thresholds deviated more than $1 S D$ from the mean threshold calculated over both groups and all six tasks. Two dyslexic readers fulfilling this criterion were found. Both had difficulties in tasks of phonological processing and nonword span, but only 1 of them fulfilled the criterion (deviation at least $1 S D$ from the control group's mean) in reading speed. This participant had severe difficulties in all other reading-related tasks. The other poor reader was ambidextrous. Two other dyslexic readers were extracted by considering poor temporal thresholds in the TOJ task or the TPA task separately. The person with poor overall TOJ acuity performed poorly in reading speed and nonword span. The person with poor TPA thresholds was impaired in reading tasks, phonological synthesis, and the nonword span task. However, the 4 dyslexic readers having poor temporal acuity did not differ from other dyslexic participants in any distinct qualitative way. For example, poor nonword span also occurred in other dyslexics.

\section{Confounding with Nontemporal Variables?}

Group differences found between the dyslexic readers and the normal readers in temporal acuity could have resulted from the dyslexic readers' poor or different overall performance in any nontemporal tasks. In addition to showing that the response biases of the two groups were similar (see the Method section) and that the threshold responses varied similarly (see Figure 3), we investigated the groups' response reliability, threshold reliability, response latency, and effects of intelligence.

Response reliability. For each participant in every task, we found the SOA value that was the threshold doubled. For example, if the threshold SOA was $100 \mathrm{msec}$, the cutoff point was $200 \mathrm{msec}$. Then, we calculated the probability of correct answers at SOAs longer (easier) than this limit. This gave an index of correct answers at easy temporal rates throughout the entire task. The probability at which the dyslexia group responded correctly on easy trials averaged over all tasks was .983, and the corresponding probability of the control group was .976 . Therefore, it is likely that both the dyslexic readers and the normal readers sustained nearly $100 \%$ response accuracy through- 
out the threshold searches in both groups as required by the instructions.

Threshold reliability. We investigated further whether we could rule out the possibility that the dyslexic readers' poorer thresholds would have resulted from difficulties in sustaining attention without lapses. We calculated Guttman split-half reliabilities from the first 6 and last 6 reversal points for each temporal threshold task, since the threshold of each task in Figure 2 can be considered to be the average of 12 reversals or 6 elementary thresholds, whose $\mathrm{CVs}$ are given in Figure 3. In the tactile, auditory, and visual TOJ tasks, the split-half reliabilities were $.54, .95$, and .52 , respectively, for the control group and $.87, .67$, and .95 , respectively, for the dyslexia group. The corresponding values in the TPA tasks were $.92, .82$, and .83 for the control group and $.82, .90$, and .84 for the dyslexia group. The reliabilities of different groups were not essentially different and were sufficient to justify the correlation analyses presented below.

Response latency. The responses of dyslexic readers might have been slower than those of normal readers. Therefore, we calculated, for each participant in every task, the total time in seconds that was required for obtaining each temporal acuity threshold. The group differences in these time values were compared with analyses of covariance in which reading group was a between-subjects factor and the temporal threshold and the number of responses in threshold search were covariates. The time values of the dyslexia and control groups did not differ statistically significantly in any task. Different response latency or speedaccuracy tradeoff did not explain the dyslexic readers' impaired temporal acuity thresholds.

Effect of memory. It is conceivable that memory load covaries with SOA. Participants with better memory could therefore have an advantage in one or more of the tasks. To control for the memory capacity, we used WAIS-R digit span backward, as forward span in itself is related to dyslexia, as an independent variable in regression analyses with each temporal acuity task separately as a dependent variable. The resulting residual (giving us a memory corrected threshold value) was used in the same analyses as the original temporal acuity variables. Taking into account the contribution of span backward diminished the group differences in auditory TPA $[t(30)=1.05, p<.16]$, but the differences in TOJ remained [tactile, $t(30)=2.03$, $p<.03$; auditory, $t(30)=1.85, p<.04]$. Therefore, although the group differences decreased, when the effects of working memory were removed from the acuity results, we could still observe statistically significant differences in tactile and auditory processing.

Effect of intelligence. It has been suggested that, in adults performing in the range of normal intelligence, matching IQ in dyslexic and normal readers is not essential, because verbal abilities affect the IQ (Nagarajan et al., 1999; Shaywitz et al., 1998). In fact, some people would like to use temporal processing measures as indices of intelligence (Vernon, 1987). We took the con- servative approach and attempted to match the IQs of the groups. Some minor nonsignificant differences remained, and, perhaps, these remaining differences might have explained the temporal acuity differences between the groups. Due to this possible criticism, we performed the same analyses as in the original data with a subgroup from which we had deleted the same number of normal readers having the highest performance IQ (PIQ) and dyslexic readers having the lowest PIQ, until we got a better PIQ for the dyslexic group than for the control group. Five participants were removed from both groups in order to meet this criterion. The IQs of the dyslexic readers and the normal readers $(N=11)$, respectively, were as follows: PIQ, 114 and 112; verbal IQ (VIQ), 107 and 111; and full IQ (FIQ), 111 and 112. Despite this curtailment, the results did not change essentially. The temporal acuity of the dyslexic readers was still worse than that of the normal readers in every TOJ and TPA task. The results presented in Figure 2 are in fact quite representative of the results of the curtailed groups, but the difference between the results of the groups was statistically significant only in the tactile TOJ task after the loss of 10 participants.

\section{Correlations Between Temporal Acuities and Reading-Related Tasks}

Correlations between temporal acuity and readingrelated tasks are presented in Table 3. In all cases, better performance in a variable is represented by a more positive score. Performance in the phonological synthesis task (and nonword span) was significantly related to temporal acuity, particularly in the tactile and auditory modalities. The actual reading or naming speeds, however, were not clearly related to temporal acuity tasks. The tactile TPA was significantly related to all WAIS-R IQs, and the auditory TOJ was significantly related to PIQ and FIQ. Additionally, WAIS-R full IQ was related to the auditory TPA. The visual tasks were not significantly related to the intelligence measures. When the significance level was corrected in order to take into account multiple comparisons (Larzelere $\&$ Mulaik, 1977), none of the correlations reached statistical significance.

To achieve a more parsimonious description of the relationships in the data, we computed a principal components analysis for the same variables (Table 4). Despite the small number of participants, a robust structure emerged, independent of rotation method. The results of the biquartimax normalized rotation are presented here, simultaneously maximizing the variances in the rows and columns. The first component, reading, explained $22 \%$ of the total variation. All the speeded reading tasks loaded on it (variance explained in word segmentation speed, 76\%; lexical decision, $67 \%$; reading speed, $65 \%$; naming speed, $36 \%$ ). The second component, temporal acuity, explained $16 \%$ of total variation. All the temporal acuity tasks and phonological synthesis loaded on this component. The third component was interpreted to reflect memory. The fourth component was hard to interpret and might have been su- 
Table 3

Correlations Between Inverted, Logarithmically Transformed Temporal Acuity Tasks and Reading-Related Tasks Over the Dyslexic Readers $(n=16)$ and the Normal Readers $(n=16)$

\begin{tabular}{|c|c|c|c|c|c|c|c|}
\hline \multirow[b]{3}{*}{ Reading-Related Task } & \multirow[b]{3}{*}{ Transformation } & \multicolumn{6}{|c|}{ Temporal Acuity Task } \\
\hline & & \multicolumn{3}{|c|}{ TOJ } & \multicolumn{3}{|c|}{$\mathrm{TPA}$} \\
\hline & & Tactile & Auditory & Visual & Tactile & Auditory & Visual \\
\hline Phonological discrimination & $+($ correct $)$ & .17 & .15 & -.06 & .10 & .07 & .02 \\
\hline Phonological synthesis & $+($ correct $)$ & $.35^{*}$ & .26 & .11 & $.47 *$ & $.50 *$ & .16 \\
\hline Letter rotation & - (seconds) & .20 & .12 & -.06 & .14 & .06 & -.14 \\
\hline Lexical decision & - (seconds) & .14 & .13 & -.10 & -.05 & .10 & -.04 \\
\hline Naming speed-RAS & - (seconds) & .17 & .33 & -.04 & -.20 & -.15 & .04 \\
\hline Word segmentation speed & $+($ correct $)$ & .15 & .13 & -.03 & .05 & .16 & .08 \\
\hline Reading speed & $+($ words/min $)$ & .24 & .17 & .00 & -.16 & -.04 & .02 \\
\hline Reading compr-fact & $+($ correct $)$ & .23 & .22 & .09 & .15 & .11 & .24 \\
\hline Reading compr-fiction & $+($ correct $)$ & .27 & .34 & .14 & .12 & .06 & .05 \\
\hline Nonword span & $+($ correct $)$ & $.48 *$ & .27 & .20 & .23 & .32 & .00 \\
\hline WAIS-R span forward & $+($ correct $)$ & .34 & .21 & .02 & .16 & .27 & .05 \\
\hline WAIS-R span backward & $+($ correct $)$ & .13 & .05 & .07 & .25 & .32 & -.07 \\
\hline WMS-R assoc learning & $+($ correct $)$ & $.39 *$ & .28 & -.03 & .16 & .18 & -.29 \\
\hline WAIS-R verbal IQ & + (quotient) & .27 & .34 & .24 & $.37 *$ & .34 & .06 \\
\hline WAIS-R performance IQ & + (quotient) & .35 & $.50 *$ & .12 & $.37 *$ & .30 & .16 \\
\hline WAIS-R full IQ & + (quotient) & .33 & $.47 *$ & .19 & $.43^{*}$ & $.38 *$ & .12 \\
\hline
\end{tabular}

$* p<.05$, Pearson product-moment correlation.

perfluous, but we kept it since it fulfilled the formal conditions. Reading comprehension-fiction, naming speed, PIQ, and auditory TOJ loaded on it.

\section{DISCUSSION}

Temporal acuity was assessed in Finnish developmentally dyslexic adults and their age- and IQ-matched controls. A majority of participants in both groups were university students. A relatively high educational level was desired in order to ensure that no participant had any learning difficulties other than poor reading. We used two methods: TOJ of two events and phase difference detection in TPA.

Three different perceptual modalities (tactile, auditory, and visual) were investigated. Their temporal threshold acuities varied widely, due to differences in stimulation and processing demands. The TPA acuity thresholds of the normal readers were $179 \mathrm{msec}$ in tactile somatosensation, $41 \mathrm{msec}$ in audition, and $45 \mathrm{msec}$ in vision. The TOJ acu-

Table 4

Principal Component Solution Over the Dyslexic Readers $(n=16)$ and the Normal Readers $(n=16)$

\begin{tabular}{llrrrr}
\hline \multirow{2}{*}{ Task } & & \multicolumn{3}{c}{ Principal Component Loadings } \\
\cline { 3 - 6 } \multicolumn{1}{c}{ Transformation } & I & \multicolumn{1}{c}{ II } & \multicolumn{1}{c}{ III } & IV \\
\hline Phonological discrimination & + (correct) & .53 & .22 & -.11 & -.20 \\
Phonological synthesis & + (correct) & .48 & .54 & .22 & -.29 \\
Letter rotation & - (seconds) & .59 & .00 & .02 & .15 \\
Lexical decision & - (seconds) & .82 & -.14 & .21 & .16 \\
Naming speed-RAS & - (seconds) & .60 & -.24 & .03 & .61 \\
Word segmentation speed & + (correct) & .87 & .03 & .19 & .01 \\
Reading speed & + (words/min) & .81 & -.17 & .24 & .21 \\
Reading compr-fact & + (correct) & .81 & .26 & .18 & -.23 \\
Reading compr-fiction & + (correct) & -.09 & .10 & .00 & .62 \\
Nonword span & + (correct) & .46 & .28 & .55 & -.07 \\
WAIS-R span forward & + (correct) & .38 & .13 & .64 & -.03 \\
WAIS-R span backward & + (correct) & .15 & .07 & .80 & -.02 \\
WMS-R assoc learning & + (correct) & -.03 & -.01 & .75 & .30 \\
WAIS-R verbal IQ & + (quotient) & .29 & .28 & .69 & .09 \\
WAIS-R performance IQ & + (quotient) & .22 & .30 & .31 & .52 \\
TOJ tactile & - (logSOA) & .16 & .62 & .26 & .41 \\
TOJ auditory & - (logSOA) & .18 & .51 & .10 & .62 \\
TOJ visual & - (logSOA) & -.07 & .64 & -.02 & .12 \\
TPA tactile & - (logSOA) & -.05 & .81 & .22 & .04 \\
TPA auditory & - (logSOA) & -.01 & .76 & .34 & .00 \\
TPA visual & - (logSOA) & .14 & .58 & -.36 & .09 \\
Explained variance $(\%)$ & & 22 & 16 & 15 & 9 \\
\hline
\end{tabular}


ity thresholds of the normal readers were $141 \mathrm{msec}$ in tactile somatosensation, $215 \mathrm{msec}$ in audition, and $29 \mathrm{msec}$ in vision. These values correspond to our own unpublished results of more than 100 university students thus far (Virsu $\&$ Oksanen, 2000). The threshold value of the auditory TOJ was high $(215 \mathrm{msec})$. Previous values of auditory TOJ have been less than 100 msec (Babkoff, 1975; Babkoff \& Sutton, 1963; Efron, 1963; Hirsh \& Sherrick, 1961; Kinsbourne et al., 1991; Sherwin \& Efron, 1980; Swisher \& Hirsh, 1972), but no previous study has used three different pitch combinations, resulting in six possible order presentations. Our auditory TOJ task was not purely temporal: It required ability to differentiate and label different pitches. With our three pitches, when the middle pitch $(1625 \mathrm{~Hz})$ was delivered first, it could have been labeled as "high" or "low" only after the presentation of the second tone. The task was also demanding on memory. The participants who could keep the pitches of all three tones in mind could have obtained better thresholds. However, controlling for memory performance in WAIS-R digit spans backward did not affect the group differences in the auditory TOJ. In TPA, the participants obtained much lower thresholds, since they did not have to label the stimuli or retain their pitches but could concentrate on temporal simultaneity or nonsimultaneity only.

\section{Pansensory Temporal Impairment in Dyslexia}

Dyslexia was associated with a generalized impairment in perceiving rapidly presented sequential nonspeech events, affecting most clearly tactile and auditory acuity. Although average temporal acuity differences varied somewhat between modalities and assessment methods, impairment became apparent to some extent in every task. No statistically reliable evidence was obtained against a pansensory impairment in the dyslexic participants. The TPA acuity thresholds of the dyslexic readers were $226 \mathrm{msec}$ in tactile somatosensation, $51 \mathrm{msec}$ in audition, and $49 \mathrm{msec}$ in vision. The TOJ acuity thresholds of the dyslexic readers were $255 \mathrm{msec}$ in tactile somatosensation, $358 \mathrm{msec}$ in audition, and $34 \mathrm{msec}$ in vision. The temporal acuity impairment was also panmethodological in the sense that it appeared similarly in order and simultaneity judgments.

Significant differences between poor and good readers were found in audition and in the tactile sense, but the acuity differences of the visual modality were not significant. The power of statistical analyses in our visual tasks was not satisfactory for no-difference conclusions, however. In many earlier results concerned with SLI (e.g., Tallal et al., 1981), poor reading (Farmer \& Klein, 1993; Laasonen et al., 2000; Reed, 1989), and average and above-average readers (Au \& Lovegrove, 2001), between-group differences in visual temporal acuity have not been significant, unlike the auditory differences. On the other hand, since visual temporal acuity differences between poor and good readers are repeatedly and similarly observed, the visual temporal acuity impairment of dyslexics could be true but small. It is possible that an impairment within the visual modality ameliorates at least partly during adolescent years (Farmer \& Klein, 1995; Tallal et al., 1981). However, our previous TPA results of 8- to 12-year-old dyslexic Finnish children (Laasonen et al., 2000) and the present results of the same three modalities indicated similar temporal acuity impairment. Therefore, our results do not support the idea that increasing age decreases the impairment in general and in vision in particular. The developmentally dyslexic readers may of course include sub-populations only some of which experience difficulties in visual temporal processing (Borsting et al., 1996; Ridder, Borsting, Cooper, McNeel, \& Huang, 1997; Slaghuis \& Ryan, 1999).

The differences between the poor readers and the normal readers in our tactile millisecond-level measures of temporal acuity support suggestions that difficulties in dyslexia are not limited to linguistic difficulties or to impairments in perceptual systems most directly involved in speech processing (audition) and reading (vision) (Stein \& Walsh, 1997; Summerfield \& Michie, 1993; Tallal, Galaburda, et al., 1993; Tallal et al., 1985). Also, functions such as postural stability or muscle tone (e.g., Fawcett \& Nicolson, 1999) and motor output (e.g., Moore, Brown, Markee, Theberge, \& Zvi, 1995; Wolff, Michel, Ovrut, \& Drake, 1990) appear to be affected in dyslexia. Several earlier studies have also indicated the pansensory nature of temporal acuity impairment of sequences in SLI (Tallal \& Piercy, 1973b; Tallal et al., 1981) and dyslexia (Kinsbourne et al., 1991; Laasonen et al., 2000).

Several control procedures indicated that the temporal acuity impairment was not due to defective performance in the nontemporal aspects of our psychophysical experiments or test performance in general. As possible sources of the temporal difference between the dyslexic readers and the normal readers, we inspected (1) response biases, (2) threshold variation (Figure 3), (3) response reliability, (4) threshold reliability, (5) response latency, (6) effect of memory, and (7) intelligence. Differences were not observed between groups in any of the tests that concerned response strategies, accuracy, attentional control, or general aspects of psychophysical or test performance. The verbal IQ, and not only PIQ, was similar in the dyslexic readers and the normal readers, although the need for IQ matching can be questioned (Nagarajan et al., 1999; Shaywitz et al., 1998). The verbal IQ of our dyslexia group was relatively high and difference between performance and verbal IQ small because verbal ability is a selection criterion to higher education: all students entering university in Finland have had instruction for at least $9+6=$ 15 years in reading, writing, and speaking two foreign languages (usually Swedish and English) in addition to studies of Finnish. The response reliability check revealed that both the dyslexic and normal readers performed similarly regarding easy, long intervals so that the differences between groups concerned only short, nearthreshold intervals between stimulus pulses. Furthermore, we were able to show that, although the groups differed genuinely in reading-related and temporal acuity tasks, there were no consistent differences in other psychometric performance or accuracy.

Good temporal acuity, independently of assessment method and modality, was related to good phonological 
awareness, as was seen from the correlations and the descriptive analysis of principal components. Auditory and visual temporal acuity in order judgment tasks has been previously linked to phonological processing and reading and spelling accuracy and speed in English (Ahissar et al., 2000; Au \& Lovegrove, 2001; Brannan \& Williams, 1988; Farmer \& Klein, 1993; Kinsbourne et al., 1991; Tallal, 1980). Here, this relationship was extended to tactile modality, order independence, and the shallow orthography of the Finnish language. Unfortunately, phonological synthesis was the only task administered to probe phonological awareness. It was selected because performance in it improves in Finnish readers at least up to the age of 15 years, at which age it can still differentiate adolescents with reading difficulties (Service et al., 1999). Performance in other tasks of phonological awareness (e.g., phonological analysis, nonword reading/spelling) is already at ceiling at the age 10 years.

The actual reading performance was not linked to temporal acuity in the present study, however. Temporal acuity could affect reading indirectly, perhaps via phonological representations. All our measures of reading were time constrained, which may have distorted correlations, given that many earlier significant correlations with reading have concerned measures of accuracy. In shallow orthographies, the reading rate of dyslexic readers has been shown to be faster than that of dyslexic readers in deep orthographies (Harris \& Hatano, 1999; Paulesu et al., 2001), although impaired phonological processing has been shown to be at least one of the core deficits in developmental dyslexia, independently of the depth of orthography (Paulesu et al., 2001). The reading experience of our highly educated adult participants also was quite extensive and could have increased the reading speed. A possible explanation for the fact that our correlations were quite low in general is that our groups represented a small, selected part of the adult population.

The acuity distributions of the dyslexic readers and the normal readers overlapped to a large extent. The dyslexic readers with poor temporal acuity could not be differentiated qualitatively from the rest of the dyslexic group. Furthermore, a discriminant analysis showed that the temporal acuity measures used did not successfully identify the participants with a history of developmental dyslexia. Our previous study with dyslexic children produced similar results (Laasonen et al., 2000). Like Bishop et al. (1999), concerning auditory temporal acuity in language-impaired children, we cannot conclude that poor temporal acuity differentiates between adult individuals with and without developmental dyslexia. Therefore, our results do not suggest a general causal role for temporal acuity impairment in dyslexia.

\section{Neural Factors in Dyslexia}

Our results agree with a neural mechanism in which a pansensory perceptual temporal acuity impairment exists in developmental dyslexia. Of the broad classes of neural explanations outlined in the introduction, the re- sults do not support the centralist hypotheses which assume that the core deficit of dyslexia is phonologicalin nature. Particularly the positive correlation of phonological synthesis with temporal acuity in general is an important piece of evidence here. The results do not support perceptual hypotheses either, because temporal acuity impairment was not sufficient for diagnosing dyslexia. Of course, it is possible that at some point in the early development, temporal impairment has been causative, preventing the normal development of reading ability. This explanation has to postulate an intermediate factor, the amelioration of temporal acuity during development, however, because temporal impairment was not sufficient for diagnosing adults. Therefore, our results seem to agree with a multifactor hypothesis least problematically.

We would like to reject amelioration as an intermediate mechanism, because our results obtained with young, well-educated adults were essentially similar to those obtained with young school children in our earlier study (Laasonen et al., 2000). We cannot exclude attention as a possible intermediate factor as an explanation of dyslexia (Hari et al., 2001; Vidyasagar, 1999), although attention cannot explain our acuity results that are insufficient to explain dyslexia. We would favor, however, the underdeveloped or deteriorated connectivity of central neurons in neural networks as a possible explanation of our results and dyslexia. This multifactor explanation is elaborated below.

Our results agree with a perceptual temporal deficit, such as that assumed in a generalized form of a magnocellular deficit (M-deficit) explanation (Galaburda \& Livingstone, 1993; Galaburda et al., 1994; Stein \& Walsh, 1997). The M-deficit, apart from impairing perceptual functions, may trigger or indicate a more extensive and general central deficit. This impairment may cause dyslexia more directly than the perceptual temporal Mdeficit itself, which is insufficient to explain dyslexia. We call our explanation of dyslexia the neural disorganization hypothesis. It postulates that the signal-to-noise $(\mathrm{S} / \mathrm{N})$ ratio of the response to rapidly changing sensory inputs is defective in dyslexia, not because of increased latency or decreased response strength but because the activation evoked by rapid changes of input diffuses temporally.

It is assumed that the amount of neural energy contained by two input signals can be the same, but the response energy can spread more or less in time so that when temporal dispersion is larger, the amplitude is lower, and vice versa. Several impulses converge into the same neuron of the brain from many different cells, and the summation of their activities within a limited time window evokes the impulses of the neuron. If a brief stimulus pulse is given, or a sudden change of stimulation occurs, the primary activation that travels several routes may reach the target neuron with more or less temporal dispersion. If the temporal dispersion is large, as in disorganized neural networks, the signal energy of the evoked response is distributed widely in time with a low amplitude and poor $\mathrm{S} / \mathrm{N}$ ratio. The detrimental temporal effect 
concerns the onset and offset of every signal, but it is significant for rapid stimulus onsets and/or offsets, brief stimuli in which the response $\mathrm{S} / \mathrm{N}$ ratio decreases more than in long signals, and sequential stimuli that follow each other at short intervals in time.

Our stimulus trains and pulses were designed with these considerations in mind. Particularly if the stimulus is periodic as in our TPA experiments, it would be expected that temporal dispersion of stimulus pulses is detrimental to temporal acuity, because the effects of response dispersion affect both the onset and offset activities of all other than the first and last pulses. We also correctly expected that TOJ and TPA methods discriminate reading groups equally because order and simultaneity should become confused similarly at acuity threshold.

The expected spread of onset and offset signal activity in time and consequent decreases in the $\mathrm{S} / \mathrm{N}$ ratio of response to brief stimuli have been observed in the brain activations of dyslexics. Evoked response techniques such as event-related potentials (ERPs) and magnetoencephalographic (MEG) responses should show temporal spread and lower amplitude, and also longer latency because of slower summation at the onset of activations. Nagarajan et al. (1999) recorded MEG responses from the auditory cortex to two 20-msec sound bursts and varied the interstimulus interval of the acoustic stimuli by 100, 200, and 500 msec. The MEG responses of poor readers to the first pulse already were later and lower in amplitude, and their effects on the responses of the second pulse 100 and $200 \mathrm{msec}$ (but not $500 \mathrm{msec}$ ) later increased the temporal spread and dramatically decreased $\mathrm{S} / \mathrm{N}$ ratio of pulse responses. Also the coherence among activations of different sensors was significantly weaker in poor readers than in good readers, as would be expected from temporal spread of activations. McAnally and Stein (1996) found in an evoked potential study that, in the brainstem responses already, the auditory temporal coding was less precise in dyslexic than in normal readers: The phase-locked discharges of dyslexics were smaller than those of controls although they were equally good at detecting a $1-\mathrm{kHz}$ tone in masking noise. Semantic MEG responses similarly indicate the decrease of S/N ratio in poor readers. Salmelin, Service, Kiesilä, Uutela, and Salonen (1996) recorded activations caused by isolated words, and Helenius, Salmelin, Service, and Connolly (1999) by sentence-ending words in different types of sentences. The semantic responses of dyslexics to the visually presented words were typically later, weaker, and vaguer than those of fluent readers.

An interesting MEG finding of Helenius, Tarkiainen, Cornelissen, Hansen, and Salmelin (1999) on Finnish adult dyslexics parallels our inability to show significantly impaired visual temporal acuity in dyslexic adults in the present study or children in an earlier study (Laasonen et al., 2000), and by others as reviewed for example by $\mathrm{Au}$ and Lovegrove (2001). The result also illustrates how an intermediate mechanism can outweigh the visual $\mathrm{M}$-deficit when reading words is concerned.
Helenius, Tarkiainen, et al. (1999) recorded MEG responses to visual symbol strings and words consisting of four letters degraded with different levels of Gaussian noise. They found that early visual responses of posteromedial extrastriate cortex up to some $100 \mathrm{msec}$ were quite similar in dyslexic and normal readers, increasing with luminance contrast. Any differences due to a significant M-deficit in dyslexic readers should have become apparent in the early responses. There actually was some difference in agreement with the M-deficits reported in the cortical recording results of dyslexic readers (Demb et al., 1998; Livingstone et al., 1991), but no early difference between the groups in MEG responses was significant. Responses to letter strings peaked around $150 \mathrm{msec}$ after word onset in the left inferior occipitotemporal area, and these were very different in poor and fluent readers. The $\mathrm{S} / \mathrm{N}$ ratio of the responses of dyslexics to stimuli having linguistic contents was strikingly poor. As compared with the late neuronal response difference caused by stimuli with linguistic contents, the early difference based on visual feature analysis and possible M-deficit in it was negligible.

\section{REFERENCES}

Ahissar, M., Protopapas, A., Reid, M., \& Merzenich, M. M. (2000). Auditory processing parallels reading abilities in adults. Proceedings of the National Academy of Sciences, 97, 6832-6837.

Au, A., \& Lovegrove, B. (2001). Temporal processing ability in above average and average readers. Perception \& Psychophysics, 63, 148-155.

BabKoff, H. (1975). Dichotic temporal interactions: Fusion and temporal order. Perception \& Psychophysics, 18, 267-272.

Babkoff, H., \& Sutton, S. (1963). Perception of temporal order and loudness judgments for dichotic clicks. Journal of the Acoustical Society of America, 35, 574-577.

Bishop, D. V., Carlyon, R. P., Deeks, J. M., \& Bishop, S. J. (1999). Auditory temporal processing impairment: Neither necessary nor sufficient for causing language impairment in children. Journal of Speech, Language, \& Hearing Research, 42, 1295-1310.

Borsting, E., Ridder, W. H., III, Dudeck, K., Kelley, C., Matsui, L., \& Motoyama, J. (1996). The presence of a magnocellular defect depends on the type of dyslexia. Vision Research, 36, 1047-1053.

Bradley, L., \& Bryant, P. E. (1978). Difficulties in auditory organisation as a possible cause of reading backwardness. Nature, 271, 746-747.

Bradley, L., \& BRyant, P. E. (1983). Categorizing sounds and learning to read: A causal connection. Nature, 301, 419-421.

Brannan, J. R., \& Williams, M. C. (1988). Developmental versus sensory deficit effects on perceptual processing in the reading disabled. Perception \& Psychophysics, 44, 437-444.

Breitmeyer, B. G. (1980). Unmasking visual masking: A look at the "why" behind the veil of the "how." Psychological Review, 87, 52-69.

Demb, J. B., Boynton, G. M., \& HeEger, D. J. (1998). Functional magnetic resonance imaging of early visual pathways in dyslexia. Journal of Neuroscience, 18, 6939-6951.

EFron, R. (1963). Temporal perception, aphasia and déjà vu. Brain, 86, 403-424.

FARMer, M. E., \& KLein, R. M. (1993). Auditory and visual temporal processing in dyslexic and normal readers. In P. Tallal, A. M. Galaburda, R. R. Llinás, \& C. von Euler (Eds.), Temporal information processing in the nervous system: Special reference to dyslexia and dysphasia (Annals of the New York Academy of Sciences, Vol. 682, pp. 339-341). New York: New York Academy of Sciences.

FARMER, M. E. \& KLEIN, R. M. (1995). The evidence for a temporal processing deficit linked to dyslexia: A review. Psychonomic Bulletin \& Review, 2, 460-493.

FAWCETT, A. J., \& Nicolson, R. I. (1999). Performance of dyslexic chil- 
dren on cerebellar and cognitive tests. Journal of Motor Behavior, 31, 68-78.

Galaburda, A. M., \& Livingstone, M. S. (1993). Evidence for a magnocellular defect in developmental dyslexia. In P. Tallal, A. M. Galaburda, R. R. Llinás, \& C. von Euler (Eds.), Temporal information processing in the nervous system: Special reference to dyslexia and dysphasia (Annals of the New York Academy of Sciences, Vol. 682, pp. 70-82). New York: New York Academy of Sciences.

Galaburda, A. M., Menard, M. T., \& Rosen, G. D. (1994). Evidence for aberrant auditory anatomy in developmental dyslexia. Proceedings of the National Academy of Sciences, 91, 8010-8013.

HARI, R., \& KIESILÄ, P. (1996). Deficit of temporal auditory processing in dyslexic adults. Neuroscience Letters, 205, 138-140.

Hari, R, Renvall, H., \& Tanskanen, T. (2001). Left minineglect in dyslexic adults. Brain, 124, 1373-1380.

Hari, R, Valta, M., \& Uutela, K. (1999). Prolonged attentional dwell time in dyslexic adults. Neuroscience Letters, 271, 202-204.

Harris, M., \& Hatano, G. (Eds.) (1999). Learning to read and write: A cross-linguistic perspective. Cambridge: Cambridge University Press.

Helenius, P., Salmelin, R., Service, E., \& Connolly, J. F. (1999). Semantic cortical activation in dyslexic readers. Journal of Cognitive Neuroscience, 11, 535-550.

Helenius P., Tarkiainen, A., Cornelissen, P., Hansen, P. C., \& SALMELIN, R. (1999). Dissociation of normal feature analysis and deficient processing of letter-strings in dyslexic adults. Cerebral Cortex, 9, 476-483.

Helenius, P., Uutela, K., \& Hari, R. (1999). Auditory stream segregation in dyslexic adults. Brain, 122, 907-913.

Hirsh, I. J., \& Sherrick, C. E. J. (1961). Perceived order in different sense modalities. Journal of Experimental Psychology, 62, 423-432.

Kinsbourne, M., Rufo, D. T., Gamzu, E., Palmer, R. L., \& Berliner, A. K. (1991). Neuropsychological deficits in adults with dyslexia. Developmental Medicine \& Child Neurology, 33, 763-775.

Kujala, T., My llyvitta, K., Tervaniemi, M., Alho, K., Kallio, J., \& NÄÄtÄNen, R. (2000). Basic auditory dysfunction in dyslexia as demonstrated by brain activity measurements. Psychophysiology, 37, 262-266.

Laasonen, M., Tomma-Halme, J., Lahti-Nuuttila, P., Service, E., \& VIRSU, V. (2000). Rate of information segregation in developmentally dyslexic children. Brain \& Language, 75, 66-81.

Larzelere, R. E., \& Mulaik, S. A. (1977). Single-sample tests for many correlations. Psychological Bulletin, 84, 557-569.

LINDEMAN, J. (1998). Ala-asteen lukutesti [Elementary school reading test]. Jyväskylä: University of Turku, Centre for Learning Research.

Livingstone, M. S., Rosen, G. D., Drislane,F. W., \& Galaburda, A. M. (1991). Physiological and anatomical evidence for a magnocellular defect in developmental dyslexia. Proceedings of the National Academy of Sciences, 88, 7943-7947.

Lovegrove, W. J. (1993). Weakness in the transient visual system: A causal factor in dyslexia? In P. Tallal, A. M. Galaburda, R. R. Llinás, \& C. von Euler (Eds.), Temporal information processing in the nervous system: Special reference to dyslexia and dysphasia (Annals of the New York Academy of Sciences, Vol. 682, pp. 57-69). New York: New York Academy of Sciences.

Lovegrove, W. J., Garzia, R. P., \& Nicholson, S. B. (1990). Experimental evidence for a transient system deficit in specific reading disability. Journal of the American Optometric Association, 61, 137-146.

Lovegrove, W. J., Martin, F., \& Slaghuis, W. (1986). A theoretical and experimental case for a visual deficit in specific reading disability. Cognitive Neuropsychology, 3, 225-267.

Lowe, A. D., \& CAmpbell, R. A. (1965). Temporal discrimination in aphasoid and normal children. Journal of Speech \& Hearing Research, 8, 313-314.

May, J. G., Williams, M. C., \& Dunlap, W. P. (1988). Temporal order judgements in good and poor readers. Neuropsychologia, 26, 917-924.

MCANALly, K. I., \& SteIN, J. F. (1996). Auditory temporal coding in dyslexia. Proceedings of the Royal Society of London: Series B, 263, 961965.

Mody, M., Studdert-Kennedy, M., \& Brady, S. (1997). Speech perception deficits in poor readers: Auditory processing or phonological coding? Journal of Experimental Child Psychology, 64, 199-231.
Moore, L. H., Brown, W. S., Markee, T. E., Theberge, D. C., \& Zvi, J. C. (1995). Bimanual coordination in dyslexic adults. Neuropsychologia, 33, 781-793.

Nagarajan, S., Mahncke, H., Salz, T., Tallal, P., Roberts, T., \& Merzenich, M. M. (1999). Cortical auditory signal processing in poor readers. Proceedings of the National Academy of Sciences, 96, 6483-6488.

Orton Dy slexia Society (1994, Fall). A new definition of dyslexia. Bulletin of the Orton Dyslexia Society.

Paulesu, E., Démonet, J. F., Fazio, F., McCrory, E., Chanoine, V., Brunswick, N., Cappa, S. F., Cossu, G., Habib, M., Frith, C. D., \& Frith, U. (2001). Dyslexia: Cultural diversity and biological unity. Science, 291, 2165-2167.

Poppen, R, Stark, J., Eisenson, J., Forrest, T., \& Wertheim, G. (1969). Visual sequencing performance of aphasic children. Journal of Speech \& Hearing Research, 12, 288-300.

REED, M. A. (1989). Speech perception and the discrimination of brief auditory cues in reading disabled children. Journal of Experimental Child Psychology, 48, 270-292.

Ridder, W. H., III, Borsting, E., Cooper, M., McNeel, B., \& Huang, E. (1997). Not all dyslexics are created equal. Optometry \& Vision Science, 74, 99-104.

Salmelin, R, Service, E., Kiesilä, P., Uutela, K., \& Salonen, O. (1996). Impaired visual word processing in dyslexia revealed with magnetoencephalography. Annals of Neurology, 40, 157-162.

Service, E, Antervo, A., Ala-Tuuhonen, K., Luukkonen, H., VIITALA, S., \& VäÄNÄNEN, T. (1999). Joitakin viitearvoja peruskoululaisten lukutaitoon liittyvissä tehtävissä [Preliminary reference values in tasks related to reading skill in comprehensive school pupils]. Psykologia, 34, 264-273.

Shankweiler, D., Liberman, I. Y., Mark, L. S., Fowler, C. A., \& FisCHER, F. W. (1979). The speech code and learning to read. Journal of Experimental Psychology: Human Learning \& Memory, 5, 531-544.

Shay witz, S. E., Shay witz, B. A., Pugh, K. R., Fulbright, R. K., Constable, R. T., Mencl, W. E., Shankweiler, D. P., Liberman, A. M., Skudlarski, P., Fletcher, J. M., Katz, L., Marchione, K. E., LACadie, C., Gatenby, C., \& Gore, J. C. (1998). Functional disruption in the organization of the brain for reading in dyslexia. Proceedings of the National Academy of Sciences, 95, 2636-2641.

Sherwin, I., \& EFron, R. (1980). Temporal ordering deficits following anterior temporal lobectomy. Brain \& Language, 11, 195-203.

SLAGHUIS, W. L., \& RYAN, J. F. (1999). Spatio-temporal contrast sensitivity, coherent motion, and visible persistence in developmental dyslexia. Vision Research, 39, 651-668.

Snowling, M. J. (2000). Dyslexia (2nd ed.). Oxford: Blackwell.

Stein, J., \& WaLSH, V. (1997). To see but not to read: The magnocellular theory of dyslexia. Trends in Neurosciences, 20, 147-152.

Summerfield, B. C., \& Michie, P. T. (1993). Processing of tactile stimuli and implications for the reading disabled. Neuropsychologia, 31, 965976.

SWISHER, L., \& Hirsh, I. J. (1972). Brain damage and the ordering of two temporally successive stimuli. Neuropsychologia, 10, 137-152.

TAllal, P. (1980). Auditory temporal perception, phonics, and reading disabilities in children. Brain \& Language, 9, 182-198.

Tallal, P., Galaburda, A. M., Llinás, R. R., \& von Euler, C. (Eds.) (1993). Temporal information processing in the nervous system: Special reference to dyslexia and dysphasia (Annals of the New York Academy of Sciences, Vol. 682). New York: New York Academy of Sciences.

Tallal, P., Merzenich, M. M., Miller, S., \& Jenkins, W. (1998). Language learning impairments: Integrating basic science, technology, and remediation. Experimental Brain Research, 123, 210-219.

Tallal, P., Miller, S., \& Fitch, R. H. (1993). Neurobiological basis of speech: A case for the preeminence of temporal processing. In P. Tallal, A. M. Galaburda, R. R. Llinás, \& C. von Euler (Eds.), Temporal information processing in the nervous system: Special reference to dyslexia and dysphasia (Annals of the New York Academy of Sciences, Vol. 682, pp. 27-47). New York: New York Academy of Sciences.

Tallal, P., \& Piercy, M. (1973a). Defects of non-verbal auditory perception in children with developmental aphasia. Nature, 241, 468469. 
TAllal, P., \& Piercy,M. (1973b). Developmental aphasia: Impaired rate of non-verbal processing as a function of sensory modality. Neuropsychologia, 11, 389-398.

Tallal, P., Stark, R. E., Kallman, C., \& Mellits, E. D. (1981). A reexamination of some nonverbal perceptual abilities of languageimpaired and normal children as a function of age and sensory modality. Journal of Speech \& Hearing Research, 24, 351-357.

Tallal, P., Stark, R. E., \& Mellits, E. D. (1985). Identification of language-impaired children on the basis of rapid perception and production skills. Brain \& Language, 25, 314-322.

Vellutino, F. R. (1978). Toward an understanding of dyslexia: Psychological factors in specific reading disability. In A. L. Benton \& D. Pearl (Eds.), Dyslexia, An appraisal of current knowledge (pp. 63111). New York: Oxford University Press.

VERNON, P. A. (Ed.) (1987). Speed of information-processing and intelligence. Norwood, NJ: Ablex.

VIDYASAGAR, T. R. (1999). A neuronal model of attentional spotlight: Parietal guiding the temporal. Brain Research-Brain Research Reviews, 30, 66-76.

VIRSU, V. (1997). Processing speed of the brain tested with periodic signals. International Journal of Psychophysiology, 25, 17.
Virsu, V., \& OKsanen, H. (2000). [Generalization of temporal learning]. Unpublished raw data.

WeCHSLER, D. (1992). Wechsler Adult Intelligence Scale-Revised: Manual. Helsinki: Psykologien Kustannus Oy.

WeChSLer, D. (1997). Wechsler Memory Scale-Revised: Manual. Helsinki: Psykologien Kustannus Oy.

Wetherill, G. B., \& Levitt, H. (1965). Sequential estimation of points on a psychometric function. British Journal of Mathematical \& Statistical Psychology, 18, 1-10.

Wimmer, H., LANDERL, K., \& Frith, U. (1999). Learning to read German: Normal and impaired acquisition. In M. Harris \& G. Hatano (Eds.), Learning to read and write: A cross-linguistic perspective (pp. 34-50). Cambridge: Cambridge University Press.

WoLF, M. (1986). Rapid alternating stimulus naming in the developmental dyslexias. Brain \& Language, 27, 360-379.

Wolff, P. H., Michel, G. F., Ovrut, M., \& Drake, C. (1990). Rate and timing precision of motor coordination in developmental dyslexia. Developmental Psychology, 26, 349-359.

(Manuscript received March 30, 2001; revision accepted for publication September 20, 2001.)

\section{Call for Papers \\ BRMIC Special Issue on Eye Movement Research Methods}

Under the joint auspices of ACM ETRA (Association for Computing Machinery's Eye Tracking Research and Applications, see http://www.vr.clemson.edukyetracking/etra/2002) and Behavior Research Methods, Instruments, \& Computers, the November 2002 issue of BRMIC will feature articles that address research methods and instrumentation related to the study of oculomotor behavior. Papers are welcomed from a variety of areas (such as Computer Science and Human-Computer Interaction; Cognitive and Social Psychology; Ergonomics; Cognitive Neuroscience; and Applied Psychology).

All interested authors are invited to submit articles for review, via a PDF file attachment to an e-mail to brmic@ hamilton.edu., prepared according to the Information for Contributors in Volume 33 (3) of BRMIC or at http://www.psychonomic.org/BRMIC/manuscript.htm

Contributions should be conspicuously marked "For the Eye Tracking issue" and be sent to the editorial office no later than March 15, 2002. Questions about submission content and format may be addressed to the General Chair of ETRA, Andrew T. Duchowski (andrewd@cs.clemson.edu) or to the editor of BRMIC, Jonathan Vaughan (brmic@ hamilton.edu). 